\title{
AVALIAÇÃO DOS NÍVEIS DE EXTRATIVISMO DA CASCA DE BARBATIMÃO [Stryphnodendron adstringens (Mart.) Coville] NO DISTRITO FEDERAL, BRASIL ${ }^{1}$
}

\author{
Henrique Cruvinel Borges Filho² e Jeanine Maria Felfili ${ }^{3}$
}

\begin{abstract}
RESUMO - Este estudo visou subsidiar o estabelecimento de diretrizes para a conservação e o manejo do barbatimão, cuja casca é usada na produção de medicamentos tradicionais, além de ser boa produtora de tanino. A coleta da casca exercida pela população é estimulada por indústrias farmacêuticas e, aos poucos, vem provocando esgotamento deste recurso. Para avaliar o dano extrativista, foram realizados sete caminhamentos, de 2 horas cada, em quatro unidades de conservação no Distrito Federal: um no Arboreto da UnB; dois na "Matinha" do Centro Olímpico da UnB, na APA do Paranoá; três na APA Gama e Cabeça de Veado; e um no Parque Ecológico Norte. Nesta ocasião, foram medidos os diâmetros (a $30 \mathrm{~cm}$ do solo), as alturas das plantas e os níveis de danos na casca provocados pelo extrativismo. Os danos foram classificados em oito níveis: $0=$ sem dano; $1=>10 \% ; 2=11-25 \% ; 3=$ $26-50 \% ; 4=51-75 \% ; 5=76-100 \%$ de casca removida; $6=$ mortas; e 7 = rebrotas. A estrutura diamétrica foi ajustada por regressão, conforme o modelo "J-invertido". A freqüência nas classes diamétricas iniciais ficou abaixo do esperado, o que indica que poderá haver redução na densidade desta espécie na porção estudada do Distrito Federal. A avaliação qualitativa indicou que $41 \%$ dos indivíduos amostrados apresentaram sinais de extrativismo desordenado independentemente do porte da planta. Deste modo, torna-se importante estabelecer políticas voltadas para o desenvolvimento de técnicas de manejo sustentado e programas de domesticação, assim como a criação de um plano gestor para as unidades de conservação no Distrito Federal.
\end{abstract}

Palavra-chave: Extrativismo, barbatimão e Stryphnodendron adstringens.

\section{EVALUATION OF EXPLOITATION LEVELS OF BARBATIMÃO BARK [Stryphnodendron adstringens (Mart.) Coville] IN DISTRITO FEDERAL, BRAZIL}

\begin{abstract}
This study provides guidelines for the conservation and management of barbatimão, whose bark is used in the production of a traditional medicine which is being commercialized by the pharmaceutical industry. Exploitation without replacement is causing the reduction of this resource. Thus, seven transects were set up in four conservation units at the Distrito Federal: one in the Arboretum - UnB, two in the Olympic Center WoodsUnB in the Paranoa APA, three in the "Gama Cabeça de Veado" APA and one in the Northern Ecological Park. The diameter and the heights of the plants were measured and the levels of bark damage caused by exploitation were registered. A two-hour walk was completed in each transect. Damage was classified in eight categories $(0=$ no damage, $1=>10 \%, 2=11-25 \%, 3=26-50 \%, 4=51-75 \%, 5=76-100 \%$ of removed bark, $6=$ dead trees and 7 = resprouts). The diameter structure was fitted to the reversed-J regression model. Frequency at the initial diameter classes was below the expected, indicating that there may be a reduction in the density of this species. Qualitative assessment indicated that two out of five individuals studied showed signs of exploitation regardless of size of the plant. Therefore, it is important to establish policies for a sustainable management plan for the conservation units in the Distrito Federal and also to develop methodologies for cultivation and sustainable management of this species.
\end{abstract}

Key words: $\quad$ Exploitation, barbatimão and Stryphnodendron adstringens.

1 Recebido para publicação em 22.7.2002.

Aceito para publicação em 9.9.2003.

2 Engenheiro Florestal, Bolsista de Aperfeiçoamento (DFID/FINATEC) do Laboratório de Manejo Florestal/Departamento de Engenharia Florestal da Universidade de Brasília - UnB, Caixa Postal 04357, 70910-900 Brasília-DF; ${ }^{3}$ Professora do Departamento de Engenharia Florestal - UnB, <cruvinel@unb.br> e <felfili@unb.br>. 


\section{INTRODUÇÃO}

O extrativismo é uma atividade que apresenta produtividade declinante, decorrente do custo de oportunidade do trabalho próximo de zero ou devido ao esgotamento do recurso com o decorrer do tempo. Esta atividade não se faz de maneira isolada, ela envolve todo um complexo rural, urbano e industrial, com vinculações nos mercados nacional e internacional (Homma, 1993).

Recentes estudos sobre a flora de cerrado apontam uma grande riqueza de espécies, aproximadamente 6.500 plantas vasculares catalogadas (Mendonça et al., 1998), sendo grande parte destas representadas por espécies úteis ao homem, por serem alimentícias, medicinais, ornamentais, forrageiras, apícolas, produtoras de madeira, cortiça, fibras, óleo, tanino, material para artesanato e outros (Funatura, 1992; IBGE 1995; Almeida et al., 1998), evidenciando, assim, sua importância no desenvolvimento da região. A disponibilidade desses recursos, aliada às necessidades humanas, possibilita o envolvimento de parte da população rural nas atividades extrativistas vegetais, nos processos de beneficiamento, industrialização e artesanatos.

No elenco das espécies úteis de cerrado, algumas têm destaque quanto ao seu valor econômico, como: aroeira (madeira), barbatimão (medicinal e tanante), buriti (alimentícia), copaíba (resina), chuveirinho (ornamental), faveira (medicinal), mangaba (frutífera), piaçava (têxtil), pequi (óleo), entre outras. Estas já possuem cadeias de mercado consolidadas, sendo capazes de gerar renda em curto prazo, entretanto poucos estudos ligados à domesticação têm sido realizados, ao passo que o potencial extrativista destas espécies tende a decrescer e, conseqüentemente, elas vêm sendo substituídas por outras atividades.

Neste trabalho, procurou-se investigar o extrativismo da casca de barbatimão (Stryphnodendron adstringens), bastante conhecida e valorizada por suas propriedades medicinais e tanantes. Partiu-se da premissa de que a pressão extrativista sobre a espécie é tão forte que ocorre mesmo em unidades de conservação e que a forma drástica com que vem sendo conduzida a coleta da casca interfere negativamente na sua estrutura populacional.

Trata-se de uma árvore comum no cerrado, com ampla distribuição geográfica, ocorrendo em vários Estados, desde o Pará, atravessando o Planalto Central, até o norte do Paraná. É encontrada, com mais freqüência, em fitofisionomias de cerrado típico, campo-sujo e cerradão (Felfili et al., 1999). Na Chapada Pratinha a abundância absoluta média variou de 2,5 a 19 indivíduos por hectare em um estudo englobando seis áreas e quatro municípios (Felfili et al., 1994). Em um cerrado típico da fazenda Água Limpa da UnB, ela está entre as dez primeiras espécies em IVI, com 34 indivíduos por hectare (Felfili et al., 1999).

No Distrito Federal, a ocupação desordenada do solo transformou a região em uma paisagem fragmentada. Os processos de expansão agrícola e a criação de novas cidades já determinaram a conversão de $56 \%$ da vegetação original (UNESCO, 2000), implicando a destruição total de áreas potenciais para o extrativismo. Os fragmentos significativos que restaram encontram-se compreendidos em unidades de conservação, sendo destinados à proteção integral e ao uso sustentável da biota existente.

Por outro lado, a melhoria dessas condições infraestruturais no Distrito Federal favorece a viabilização de atividades extrativistas, com a melhora das perspectivas de mercado e com a redução dos custos de extração. As áreas urbanas ficaram próximas às áreas rurais, facilitando o escoamento dos produtos para os mercados consumidores (centros urbanos e feiras) e diminuindo o custo de transporte.

No que se refere ao cenário nacional, tudo indica que a casca de barbatimão está em fase de declínio, seja por esgotamento do recurso ou pela substituição da atividade extrativista por outras, como a agricultura e a pecuária. Dados disponibilizados pelo Instituto Brasileiro de Geografia e Estatística (IBGE, 2000) apontam que a produção de casca de barbatimão decresceu de 1.500 para apenas 12 toneladas/ano no período de 1988 a 2000.

Os objetivos deste trabalho foram qualificar e quantificar os níveis de danos extrativistas, analisar a estrutura diamétrica das populações amostradas e pesquisar a comercialização deste produto nas principais farmácias de Brasília-DF. Espera-se contribuir para o delineamento de estratégias sustentáveis para a conservação e o manejo do barbatimão.

\section{MATERIAL E MÉTODOS}

\section{1. Áreas Amostradas}

Foram selecionadas quatro unidades de conservação com domínio de fitofisionomias de cerrado típico, todas 
localizadas na bacia do Paranoá (Figura 1) e compreendidas na zona urbana de consolidação do Distrito Federal, conforme o Plano Diretor de Ordenamento Territorial do DF (PDOT). Atualmente, estas unidades vêm sofrendo forte pressão antrópica, estando ilhadas pela malha urbana.

O Arboreto da Universidade de Brasília (ARBO) foi criado em 23 de janeiro de 1991 pelo Ato ${ }^{\circ}$ 090/91, na administração do Reitor Antônio Ibañes, destinado à conservação e recuperação da biota nativa do cerrado e à educação científica. Seus limites compreendem a área situada entre as vias L-2 e L-4 norte, na altura das quadras 808 a 816 , totalizando por uma área natural de 43 ha. De acordo com as categorias de manejo de unidades de conservação, enquadra-se como área de relevante interesse ecológico, pois engloba as margens de um curso d'água cobertas por matas de galeria, algumas nascentes (áreas de preservação permanente), além de áreas degradadas por empréstimo de cascalho na época da construção de Brasília, já que estão em processo de recuperação.
A "Matinha" do Centro Olímpico da Universidade de Brasília (CO) situa-se ao redor do Lago Paranoá, no setor de clubes norte, ao lado da Casa do Estudante Universitário e Administração Central do IBAMA. Possui 80 ha de cerrado e um pequeno fragmento de mata de galeria, que estão integrados à área de proteção ambiental do Lago Paranoá, criada pelo Decreto $\mathrm{n}^{\circ} 12050$ de 1989.

A APA Gama e Cabeça de Veado (APA) foi criada pelo Decreto no 9417 de 21 de abril de 1986, pelo Governo do Distrito Federal. A APA possui uma área de aproximadamente 25.000 ha, localizada entre as coordenadas $15^{\circ} 52^{\prime}$ ' e $15^{\circ} 59^{\prime}$ sul e $47^{\circ} 50^{\prime}$ e $47^{\circ} 58^{\prime}$ 'WGr. Constituem partes integrantes da APA a fazenda Água Limpa, que contém uma estação ecológica e é administrada pela Universidade de Brasília, com 4.040 ha; a Reserva Ecológica do IBGE, com 1.360 ha; e o Jardim Botânico, com 5.000 ha. Estas reservas, junto com as áreas marginais aos córregos em uma extensão de $80 \mathrm{~m}$, constituem a zona de vida silvestre da APA. Além das

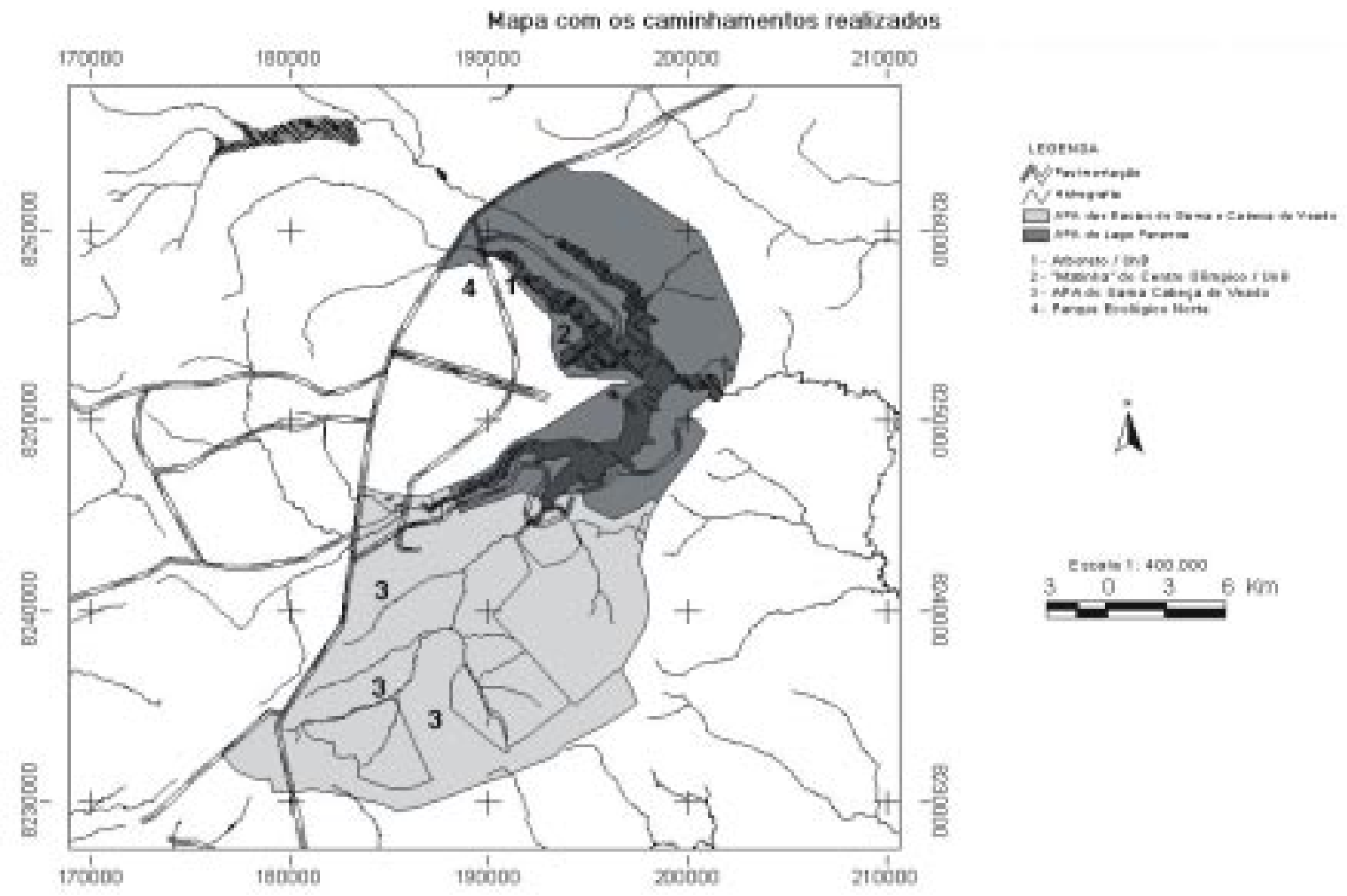

Figura 1 - Localização dos caminhamentos: (1) Arboreto UnB; (2) "Matinha” do Centro Olímpico UnB; (3) APA do Gama Cabeça de Veado; e (4) Parque E cológico Norte, Brasília, DF.

Figure 1 - Location of transects: (1) UnB's Arboretum; (2) UnB's “Matinha” Centro Olímpico; (3) Gama - Cabeça de Veado APA; (4) Parque E cológico Norte, Brazilia, DF. 
áreas de proteção integral estão incluídas áreas rurais e urbanas de propriedade particular, que foram objeto da amostragem, como o setor de mansões Park Way, bairro residencial onde os lotes mínimos são de $2.500 \mathrm{~m}^{2}$, formando condomínios de até oito lotes em $20.000 \mathrm{~m}^{2}$. Neste bairro encontram-se invasões na forma de chácaras nas bordas dos córregos e também o Núcleo Hortícola de Vargem Bonita, vizinho à fazenda Água Limpa. Estas áreas formam reservas com graus variados de proteção e têm permitido diversas atividades de ensino e pesquisa, assim como atividades de uso direto. Neste setor foram estabelecidas três áreas de estudo: a fazenda Água Limpa, considerada unidade de proteção integral, e duas áreas como unidade de uso direto.

O Parque Ecológico Norte (PqEN) fica adjacente à Asa Norte, compreendido entre as vias W5 norte e a rodovia DF-030, na altura das quadras de 908 a 916 norte. O parque, que conta com aproximadamente 175 ha, tem como objetivo a proteção de atributos naturais perto das áreas urbanas, com finalidades educacionais, recreativas e científicas, permitindo o uso mais intenso. Atualmente vem sofrendo com as invasões, que, paulatinamente, desfiguram sua paisagem original.

\subsection{Coleta dos Dados}

Foi realizado um inventário florestal de cunho estratégico com abrangência regional (Péllico Netto \& Brena, 1997), utilizando um procedimento padronizado de amostragem, onde a unidade amostral foi fixada em função do tempo. Optou-se pelo método de caminhamento, descrito por Filgueiras et al. (1994), por um período padronizado de 2 horas cada, devido à rapidez $\mathrm{e}$ à eficiência proporcionadas pelo método, tendo em vista que os espécimes de $S$. adstringens estão distribuídos aleatoriamente em campo. Foram feitos sete caminhamentos no total:

- um no Arboreto da Universidade de Brasília;

- um no Parque Ecológico Norte;

- dois no Centro Olímpico da Universidade de Brasília; e

- três na Área de Proteção Ambiental do Gama Cabeça de Veado, sendo um foi na fazenda Água Limpa da Universidade de Brasília, em área protegida, e os outros dois em áreas de uso direto, no setor de manções Park Way, quadras 14, 15, 16, e 17.

Nessa ocasião, foram medidos os diâmetros de todos os indivíduos observados a partir de $3 \mathrm{~cm}$ (a $0,30 \mathrm{~m}$ do solo) e feito registro visual do nível de dano extrativista encontrado na casca.

\subsection{Avaliação dos Dados}

Para avaliação qualitativa, foi criado um sistema de classificação ordinal com base no nível porcentual de casca extraída encontrado em caules e ramos, até a altura de $2 \mathrm{~m}$ para cada indivíduo observado, seguindo uma escala de oito pontuações (Figura 2), sendo a pontuação $0=$ sem dano; $1=<10 \%$ de casca removida; $2=10-25$; $3=26-50 \% ; 4=51-75 ; 5=76-100 \% ; 6=$ morta $;$ e $7=$ tronco principal morto, mas com rebrota [adaptação do método descrito por Cunningham (1991)]. Foi calculado o coeficiente de correlação entre a medida do diâmetro do caule e a pontuação de cada nível de dano, para constatar se existia um critério de escolha dos indivíduos a serem explorados quanto ao porte.

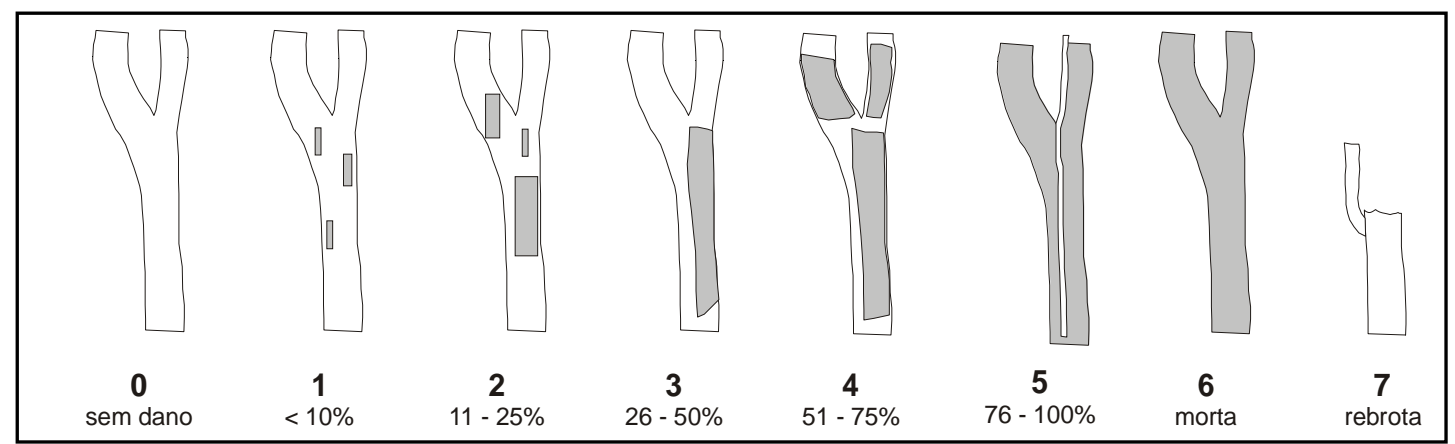

Figura 2 - Classificação ordinal dos níveis de danos encontrados na casca dos indivíduos amostrados, até altura de $2 \mathrm{~m}$ (linha pontilhada), Brasília-DF.

Figure 2 - Ordinal classification of damage levels found on the bark of the trees, up to $2 \mathrm{~m}$ high (dotted line), Brazilia, DF. 
A estrutura diamétrica foi ajustada ao modelo "J-invertido" $\left(\mathrm{LnY}=\mathrm{b}_{0}+\mathrm{b}_{1} \mathrm{X}\right)$ ou exponencial negativo, visando constatar se existiam problemas de regeneração natural atribuída a intervenções extrativistas. Foram também calculados os coeficientes "q" de Liocourt (Meyer, 1952; Meyer et al., 1961).

\subsection{Fonte de Dados sobre o Comércio da Casca do Barbatimão}

No que se refere à comercialização desta matériaprima, foram realizadas visitas às principais farmácias homeopáticas de Brasília, avaliando-se os preços finais dos medicamentos e as principais empresas do mercado do Distrito Federal e brasileiro.

\section{RESULTADOS E DISCUSSÃO}

\subsection{Avaliação Qualitativa}

\subsubsection{Níveis de Danos}

A distribuição total dos níveis de danos (Figura 3-h) mostra que $41 \%$ do dos indivíduos observados (equivalente a 244 indivíduos) apresentaram sinais de extrativismo, devendo ser ressaltado que $11 \%$ (64 indivíduos) tiveram até $10 \%$ de casca extraída, $10 \%$ (57 indivíduos) até $25 \%, 6 \%$ (36 indivíduos) até 50\%, 4\% (23 indivíduos) até $75 \%$ e $1 \%$ (seis indivíduos) até 100\%, enquanto 3\% (30 indivíduos) estavam mortos e 6\% (38 indivíduos) apresentaram o tronco principal morto, a)

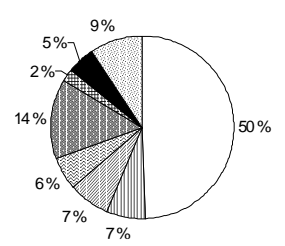

d)

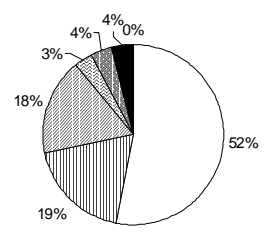

g)

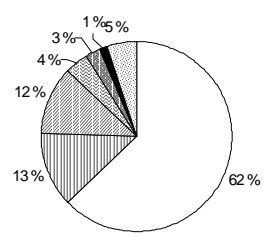

b)

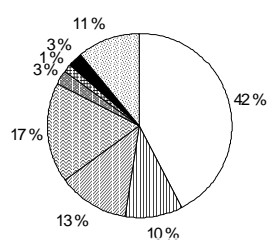

e)

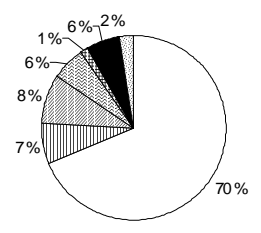

h)

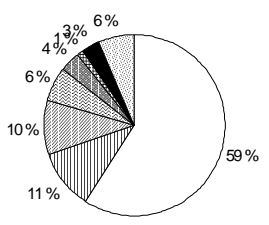

c)

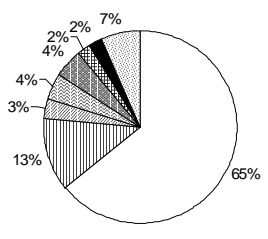

f)

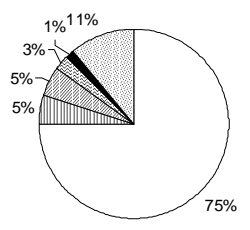

Figura 3 - Distribuição dos danos por local amostrado: (a) Arboreto da UnB (ARBO), (b) Caminhamento 1 na "Matinha" do Centro Olímpico da UnB (CO.1), (c) Caminhamento 2 na "Matinha" do Centro Olímpico da UnB (CO.2), (d) Caminhamento 1 na APA do Gama - Cabeça de Veado (APA.1), (e) Caminhamento 2 da APA do Gama - Cabeça de Veado, (f) Fazenda Água Limpa da UnB (FAL), (g) Parque E cológico Norte (PqEN) e (h) Total observado.

Figure 3 - Damage distribution by locality sampled: (a) UnB's Arboretum (ARBO), (b) transect 1 in the UnB's "Matinha" do Centro Olimpico (CO.1), (c) transect 2 in the UnB's "Matinha" do Centro Olímpico (CO.2), (d) transect 1 in the Gama Cabeça de Veado APA (APA.1), (e) transect 2 in the Gama Cabeça de Veado APA, (f) UnB's Fazenda Água Limpa (FAL), (g) Parque E cológico Norte (PqEN) and (h) Total observed. 
mas com rebrota. Os demais indivíduos observados (59\% ou 353 indivíduos) não apresentaram danos.

Portanto, dentre os indivíduos que tinham sinais de extração apenas $11 \%$ sofreram baixo impacto, enquanto 87 indivíduos (36\%) sofreram extração de mais de $50 \%$ da casca, que é considerada elevada.

As distribuições dos danos por local foram separadas em três grupos, conforme caracterização e intensidade das perturbações (Figura 3):

1) Perturbações leves: os resultados encontrados na FAL (Figura 3-f) mostram que 75\% de indivíduos não apresentam sinais de extrativismo, o que se deve ao fato de o local ser patrulhado e com pouca presença de trânsito humano. Neste as lesões são causadas pelo descascamento natural e por lesões originadas ou causadas por queimadas, e não propriamente por extração. A diferença encontra-se no tamanho e na uniformidade das lesões, porém foram registrados, em pequenas quantidades, casos de extração. As lesões conseqüientes da extração da casca são maiores e uniformes, onde se vê a marca certeira dos cortes, comparados com o descascamento natural, que são menores e desiguais.

2) Perturbações moderadas: os resultados encontrados no CO.2, APA.1, APA.2 e PqEN (Figura 3-c, d, e, g) mostram que, respectivamente, $65,52,70$ e $62 \%$ dos indivíduos observados não apresentam sinais de extração, ressaltando-se que CO.2 e PqEN são áreas protegidas, de uso indireto, enquanto as áreas particulares da APA.2 e APA.1 permitem o uso direto com restrições, mas por outro lado são áreas com baixa densidade populacional.

3) Perturbações severas: já para os resultados encontrados no ARBO e CO.1 (Figura 3-a, b), 50 e 42\%, respectivamente, dos indivíduos observados não apresentaram sinais de extrativismo. Este fator pode está correlacionado com a proximidade da zona urbana, o que facilita a ação dos extratores, assim como sofre influência antrópica devido a invasões ali instaladas. Além disto, freqüentemente transitam pessoas que trabalham no Setor de Clubes Norte.

\subsubsection{Níveis de Danos por Classes Diamétricas}

A Figura 4 permite analisar a forma como está sendo extraída a casca do $S$. adstringens. As distribuições dos danos por classes diamétricas foram:

R. Árvore, Viçosa-MG, v.27, n.5, p.735-745, 2003
- Para a primeira classe diamétrica, dentre os 253 indivíduos entre 3 e $7 \mathrm{~cm}$ de diâmetro, 81 (equivalente a $32 \%$ ) apresentaram sinais de extrativismo, devendo ser ressaltado que $21(8 \%)$ indivíduos apresentaram até $10 \%$ de casca extraída, $13(5 \%)$ até $25 \%$ e (4\%) até $50 \%$, enquanto $6(2 \%)$ indivíduos estavam mortos e 32 apresentavam rebrotas $(13 \%)$.

- Dentre aqueles 193 indivíduos entre 7 e $11 \mathrm{~cm}$ de diâmetro, 79 (equivalente a 41\%) apresentaram sinais de extrativismo, tendo 21 indivíduos (equivalente a 10\%) apresentado até $10 \%$ de casca extraída, $29(15 \%)$ até $25 \%$, 14 indivíduos $(7 \%)$ até $50 \%$ e $5(3 \%)$ até $75 \%$, enquanto $7(4 \%)$ indivíduos estavam mortos e $3(2 \%)$ apresentavam rebrotas.

- Dentre os 83 indivíduos com 11 a 15 cm, 34 (equivalente a $41 \%$ ) apresentaram sinais de extrativismo, tendo 11 indivíduos (equivalente a 13\%) apresentado até $10 \%$ de casca extraída, $9(11 \%)$ até $25 \%, 4(5 \%)$ até $50 \%$ e $2(2 \%)$ até $75 \%$, enquanto $(7 \%) 6$ indivíduos estavam mortos e $2(2 \%)$ apresentavam rebrotas.

- Dentre os 40 indivíduos entre 15 e 19 cm de diâmetro, 25 (equivalente a 63\%) apresentaram sinais de extrativismo, tendo cinco (equivalente a 13\%) apresentado até $10 \%$ de casca extraída, $3(8 \%)$ até $25 \%, 6(15 \%)$ até $50 \%, 5(13 \%)$ até $75 \%, 1(3 \%)$ até $100 \%$, e $1(3 \%)$ morto e $4(10 \%)$ rebrotas.

- Dentre os 14 indivíduos entre 19 e $23 \mathrm{~cm}$ de diâmetro, 9 (equivalente a 69\%) apresentaram sinais de extrativismo, tendo 4 (equivalente a 31\%) apresentado até $10 \%$ de casca removida, 1 (equivalente a $8 \%$ ) até $50 \%, 3(23 \%)$ até $75 \%$ e $1(8 \%)$ até $100 \%$.

- Todos os indivíduos entre 23 e $27 \mathrm{~cm}$ de diâmetro apresentaram sinais de extrativismo, tendo 2 (equivalente a $25 \%$ ) apresentado até $10 \%$ de casca extraída, 2 (equivalente a $25 \%)$ até $25 \%, 3(38 \%) 75 \%$ e $1(12 \%)$ até $100 \%$.

- Apenas um dos indivíduos entre 27 e $31 \mathrm{~cm}$ não apresentou dano, tendo 1 indivíduo apresentado até $25 \%$ de casca extraída, 2 até $50 \%$ e 1 até $75 \%$.

Considerando todas as áreas em conjunto, verificase que todos os indivíduos amostrados com mais de $23 \mathrm{~cm}$ de diâmetro apresentam vestígios de extração, com exceção de apenas um indivíduo no "Matinha" do Centro Olímpico da UnB (CO). 


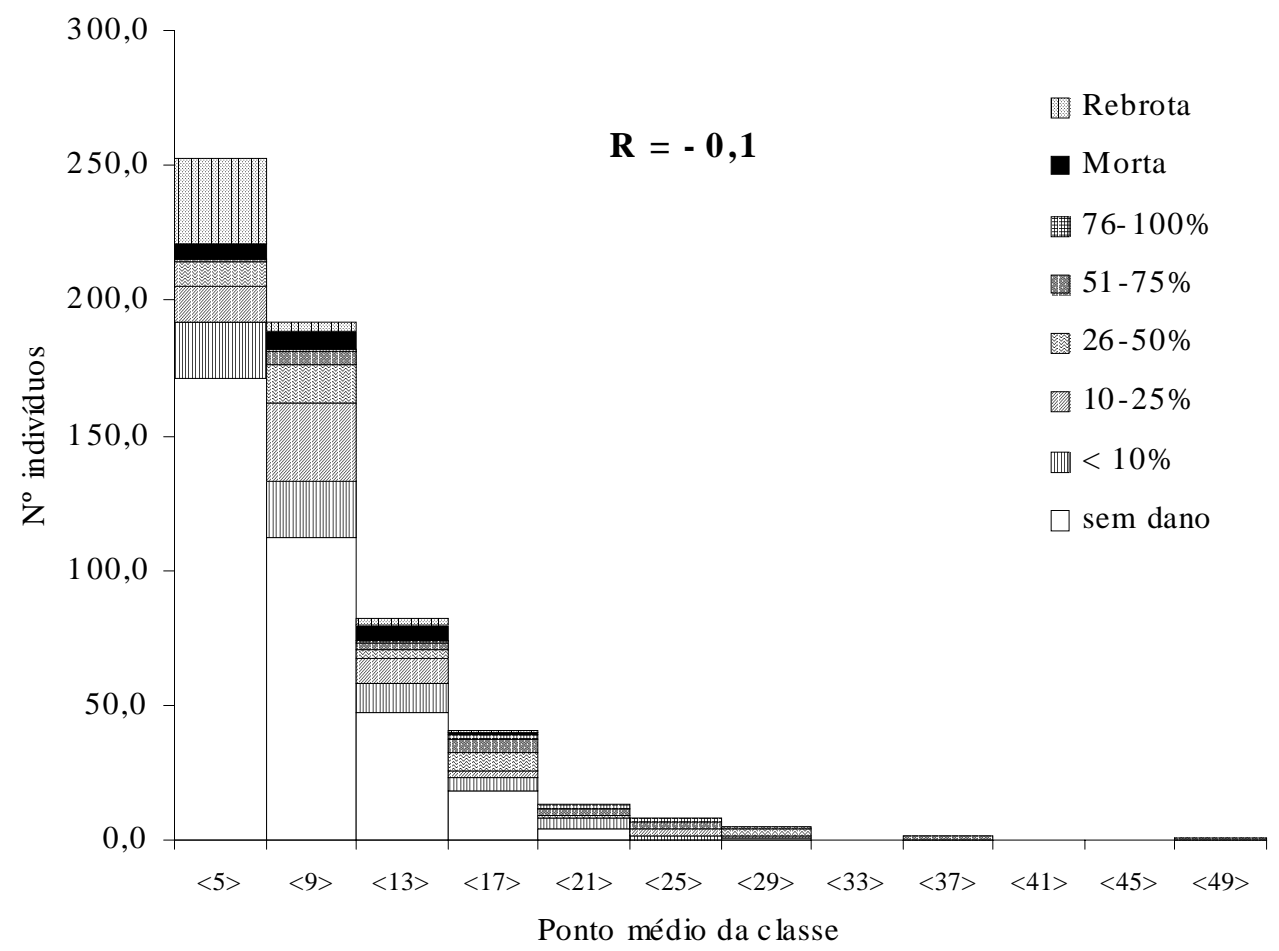

Figura 4 - Distribuição dos danos por estrutura diamétrica e coeficiente de correlação (R), Stryphnodendron adstringens, Brasília-DF.

Figure 4 - Damage distribution by diameter structure and correlation coeficient (R), Stryphnodendron adstringens, Brazilia, DF.

O coeficiente de correlação de Pearson foi baixo, de $-0,1$, indicando que a extração é feita sem critério de seleção dos indivíduos quanto ao porte.

A coleta da casca está sendo feita de modo desordenado e prejudicial à manutenção das populações, mesmo em unidades de conservação. Nem os indivíduos menores (regeneração natural) escaparam da ação extrativista, tornando-se, também, mais suscetíveis à ação do fogo.

Barros (1997), trabalhando com plantas medicinais, já havia mencionado que o uso e o conhecimento das propriedades medicinais das espécies do cerrado, em geral, estão nas mãos de leigos (mateiros e raizeiros). O uso das plantas está relacionado aos costumes locais, que consistem na extração de maneira predatória das estruturas vegetativas e reprodutivas: raízes, folhas, bulbos, cascas, plantas inteiras etc.

Verificou-se, também, que a coleta da casca em caules finos provoca deformações estruturais na planta, tornando-as frágeis fisicamente, portanto elas se quebram facilmente com a ação dos ventos. Além disto, a coleta da casca pode afetar a longevidade da planta, pois nela estão presentes os tecidos condutores da seiva elaborada (floema), que funciona como protetor do tecido meristemático do câmbio, responsável pelo crescimento secundário, prejudicando, assim, o desenvolvimento da planta (Guedes, 1993).

\subsection{Estrutura das Populações}

\subsubsection{Distribuição Diamétrica}

Foram observados 597 indivíduos no total, que foram separados proporcionalmente em sete classes diamétricas, optando-se por intervalos de classe igual a $4 \mathrm{~cm}$. A estrutura diamétrica das populações seguiu o padrão "J - invertido" (Figura 5-h). Mais de 40\% dos indivíduos apresentaram diâmetros inferiores a $9 \mathrm{~cm}$ e menos de $1 \%$ atingiram até $31 \mathrm{~cm}$ de diâmetro.

A tendência decrescente da primeira para a última classe indica a possibilidade de auto-regeneração. Porém, 
a comparação da distribuição atual com a curva ajustada pelo modelo de regressão indica que o recrutamento está abaixo do esperado na primeira classe diamétrica, evidenciando que poderá haver uma redução na densidade desta espécie na porção estudada do DF.

Com base no cálculo do modelo de regressão "J-invertido" para os dados de todas as áreas, chegou-se à equação $\operatorname{LnY}=6,6982-0,1844 \mathrm{X}$, com $\mathrm{R}^{2}$ na ordem de 0,99 (linha de tendência exibida na Figura 5-h). Os valores encontrados para as razões "q" variam em torno de 0,5 , com exceção da primeira classe diamétrica, que apresentou valor elevado.

A maioria dos indivíduos atingiu até $10 \mathrm{~cm}$ de diâmetro e os maiores indivíduos atingiram em torno de $30 \mathrm{~cm}$, conforme já constatado por Felfili \& Silva Júnior (1988) para esta espécie. Porém, nas áreas do Arboreto UnB e da "Matinha" Centro Olímpico - UnB foram registrados um indivíduo com diâmetro de 49,6 cm e dois com 36 e $37 \mathrm{~cm}$, respectivamente. Observou-se que a extração da casca provocou espessamento do câmbio remanescente, produzindo um caule bastante irregular, que foi a causa dessa discrepância.

Os resultados encontrados nos caminhamentos $\mathrm{CO} .2$ e FAL (Figura 5-a, b) ajustam-se ao modelo de "J invertido", $\mathrm{R}^{2}$ na ordem de 0,9897 e 0,9775 , respectivamente; nota-se que razões q variam em torno de 0,5 , o que indica possibilidades de auto-sustentação.

No ARBO, CO.1 e PqEN (Figura 5-c, d, e), com R ${ }^{2}$ na ordem de 0,9626, 0,8058 e 0,7779, respectivamente, constatou-se uma tendência de "J invertido", mas com bastante discrepância na relação entre as primeiras classes de diâmetro e as subseqüentes, o que indica que poderá haver um acréscimo de indivíduos; nota-se que a razão q2 do ARBO e as razões q1 do CO.1 e PqEN são baixas, isto é, $0,31,0,35$ e 0,39 , respectivamente.

Já nos caminhamentos APA.1 e APA.2 (Figura 5-f, $\mathrm{g}$ ), com os $\mathrm{R}^{2}$ na ordem de 0,8976 e 0,5784 , respectivamente, um número menor de indivíduos nas classes iniciais indica problemas de regeneração natural. Observa-se que as razões q iniciais são altas, dado pelos respectivos valores 1,51 e 1,39.

Outro fator de desequilíbrio das populações é a associação do extrativismo com as queimadas freqüentes na região. A perda da casca deixa os indivíduos da espécie desprotegidos quando submetidos a altas temperaturas, acentuando assim sua vulnerabilidade, principalmente

R. Árvore, Viçosa-MG, v.27, n.5, p.735-745, 2003 daqueles mais jovens. Guedes (1996), em seus estudos, acrescenta que a casca funciona como isolante térmico, protegendo o câmbio contra a ação do fogo.

Há, portanto, a necessidade de um melhor manejo da vegetação e de enriquecimento da regeneração em algumas das áreas estudadas.

\subsection{O Comércio da Casca de Barbatimão}

O comércio de plantas medicinais no Brasil tem demonstrado ser bastante lucrativo, segundo relatório preliminar elaborado pelo IBAMA. No período de 1994 a 1997 foram exportadas quase 4,5 mil toneladas de plantas medicinais para Alemanha, Austrália, Estados Unidos, Japão, Coréia, entre outros, rendendo ao País cerca de 22,5 milhões de dólares neste mesmo período, sendo a maior fornecedora a Floresta Amazônica, seguida da Mata Atlântica e do cerrado.

O barbatimão é uma das principais espécies comercializadas oriundas de cerrado, sendo o Estado de Minas Gerais o principal produtor, seguido de outros com pequena participação, como Pará, Bahia e Goiás (Almeida, 1998). A produção nacional de barbatimão decresceu de 1.500 para 12 toneladas/ano no período de 1988 a 2000 (Almeida, 1998; IBGE, 2000).

No Distrito Federal existem dezenas de empresas que comercializam plantas medicinais, sendo estas farmácias homeopáticas, farmácias de manipulação e laboratórios farmacêuticos. As principais farmácias do DF são: Farmacotécnica Ltda., Pharmagreen, Manipulatum, União, Dom Bosco, Botica Farmácia Homeopática, Pharmakon, entre outras. São vendidos partes, produtos e subprodutos de plantas, como folhas, frutos, sementes, casca, pó, extratos, óleos e raízes. No entanto, nenhuma farmácia possui reserva extrativista ou cultiva espécies nativas, e nem recebe essa exigência por parte dos órgãos governamentais.

As principais empresas brasileiras fornecedoras de produtos derivados do barbatimão para o Distrito Federal são: Ambrosifarma Ltda., Quimer Ltda, Klein Ltda., Laboratório Centroflora Ltda., Laboratório Farmaervas Ltda., A Natureza Prod. Farm. Ltda. e Farmacotécnica Ltda., sendo esta última a única empresa do Distrito Federal que cultiva suas próprias plantas, mas o cultivo é restrito apenas às ervas tradicionais da medicina caseira e já domesticadas, não incluindo o barbatimão. 

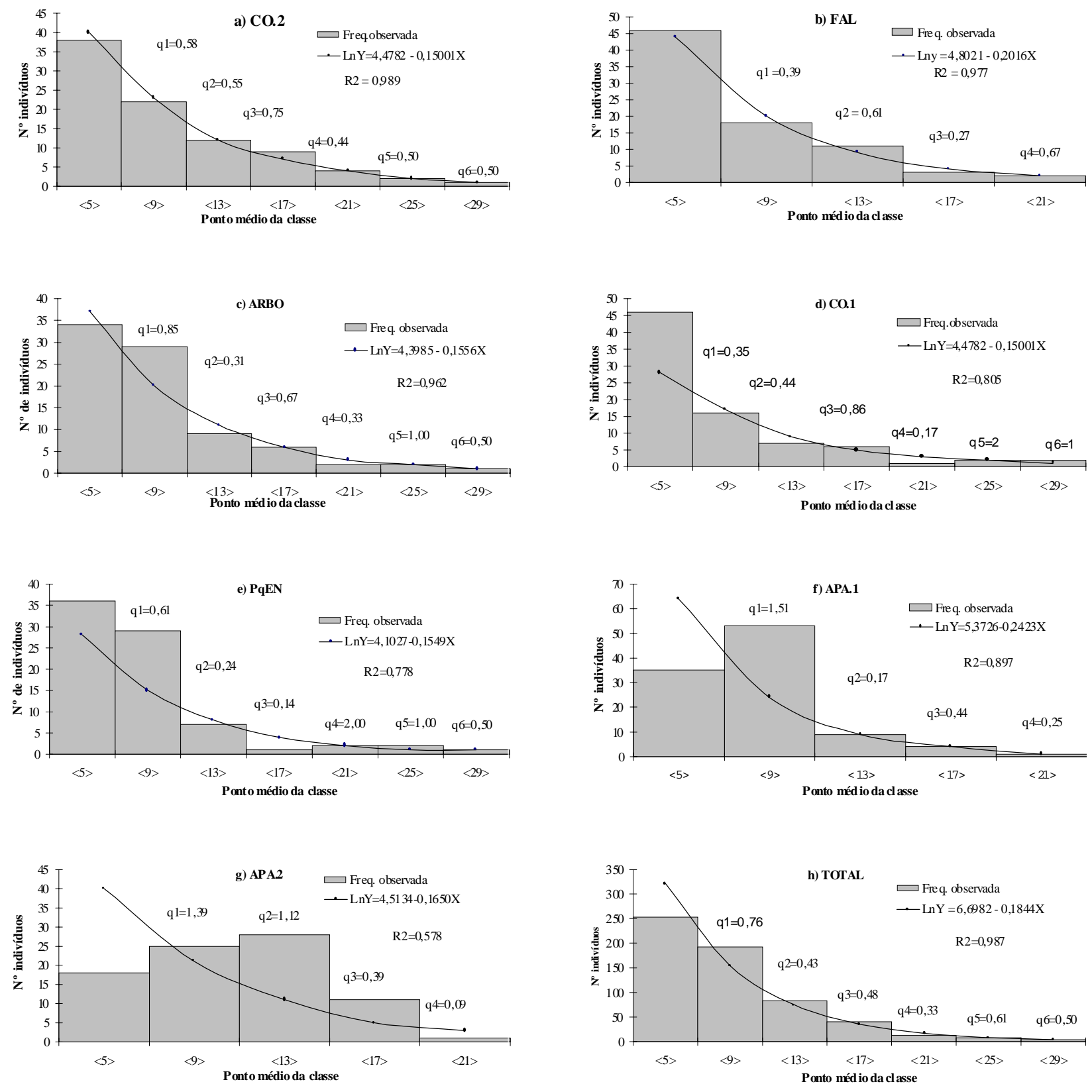

Figura 5 - Distribuição diamétrica por local amostrado sob curva de ajuste "J -invertido" (LnY = B0 + b1X), coeficiente de Liocourt " $\mathrm{q}$ " e coeficiente de determinação " $\mathrm{R}^{2 ": ~(a) ~ C a m i n h a m e n t o ~} 2$ da "Matinha" do Centro Olímpico da UnB (CO.2); (b) Fazenda Água Limpa da UnB (FAL); (c) Arboreto da UnB (ARBO); (d) Caminhamento 1 da "Matinha" do Centro Olímpico da UnB (CO.1); (e) Parque E cológico Norte (PqEN); (f) Caminhamento 1 da APA do Gama - Cabeça de Veado (APA.1); (g) Caminhamento 2 da APA do Gama - Cabeça de Veado e (h) Distribuição diamétrica total (TOTAL), Brasília-DF.

Figure 5 - Diameter disdtribution by locality sample under "reversed-J " curve (LnY = B0 + b1X), Liocourt coeficient " $q$ " and determination coeficient "R2": (a) Transect 2 in the UnB's "Matinha" do Centro Olímpico (CO.2); (b) UnB's Fazenda Água Limpa (FAL); (c) UnB's Arboretum (ARBO); (d) Transect 1 in the UnB's "Matinha" do Centro Olímpico (CO.1); (e) Parque E cológico Norte (PqEN); (f) Transect 1 in the Gama - Cabeça de Veado APA (APA.1); (g) Transect 2 in the Gama - Cabeça de Veado APA; e (h) Total diameter distribution (TOTAL), Brazilia, DF. 
O produto devidamente processado e embalado é vendido em forma de chá, cápsula e líquido. Segundo entrevista realizada com os comerciantes, no período de 2001, o chá é o mais vendido, com preços variando entre $\mathrm{R} \$ 3,50$ e $\mathrm{R} \$ 12,00$ por $100 \mathrm{~g}$ de chá, entre $\mathrm{R} \$ 6,00$ e $\mathrm{R} \$ 10,00$ por $100 \mathrm{ml}$ de líquido e entre $\mathrm{R} \$ 9,00$ e $\mathrm{R} \$ 20,00$ por 120 unidades de cápsulas.

\section{CONCLUSÃO}

A coleta da casca de barbatimão é feita de forma desordenada, sem critério de escolha dos indivíduos, o que coloca a espécie sob risco de extinção, caso a expansão agrícola a urbana se intensifiquem. $O$ trabalho permitiu estimar que dois em cada cinco (41\%) indivíduos amostrados em unidades de conservação de uso direto apresentaram sinais de extrativismo depredatório.

Em geral, a forma como vem sendo conduzida a coleta da casca desta espécie é insustentável para todos os níveis encontrados, portanto recomenda-se o emprego de técnicas de manejo sustentável, protocolos de extração e proteção de áreas contra o fogo. Através de podas e cortes de melhora obtém-se a casca e, ao mesmo tempo, beneficia-se o incremento dos indivíduos selecionados.

A proximidade de centros urbanos e o abandono das áreas têm sido os principais fatores de perturbação das populações de $S$. adstringens, facilitando a ação dos extratores. Trechos como o do Arboreto - UnB e "Matinha" do Centro Olímpico mostraram-se severamente perturbados em função dos fatores citados, merecendo vários tratamentos para sua recuperação e seu beneficiamento.

Essas unidades de conservação encontram-se sem a devida estrutura de fiscalização, de proteção e de aplicação dos objetivos para quais foram criadas, como os de conservação in situ da biota existente, educação ambiental e pesquisas ecológicas, o que facilita o acesso ao recurso de qualquer pessoa para coletar a casca.

Na única unidade de conservação de uso indireto, a fazenda Água Limpa, que tem um sistema de gerenciamento e fiscalização, não foi constatada atividade extrativista e a estrutura da população indica equilíbrio.

Sugere-se que as empresas identificadas como fornecedoras dos produtos de barbatimão mantenham áreas sob extrativismo sustentável e, ou, iniciem programas de plantio comercial da espécie.

R. Árvore, Viçosa-MG, v.27, n.5, p.735-745, 2003

\section{AGRADECIMENTO}

Ao CNPq, ao IBAMA e ao projeto Conservação e Manejo da Biodiversidade do Bioma Cerrado - DFID e FINATEC. À Renata R. Maranhão, pela elaboração do mapa com os caminhamentos estudados.

\section{REFERÊNCIAS BIBLIOGRÁFICAS}

ALMEIDA, S. P.; SANO, S. M. (Eds). Cerrado: espécies vegetais úteis. Brasília: EMPRAPA Cerrado, 1998. p. 347351.

BARROS, M. A. G. Avaliação da ação antrópica sobre as plantas do cerrado com potencial econômico. In: LEITE, L. L.; SAITO, C. H. (Eds.) Contribuição ao conhecimento ecológico do cerrado: trabalhos selecionados do $3^{\circ}$ Congresso de Ecologia do Brasil. Departamento de Ecologia. Brasília: Universidade de Brasília, 1997. p. 257-261.

CUNNINGHAN A. B. Development of a conservation policy on commercially exploited medicinal plants: A case study from Southern Africa. In: AKERELE O.; HEYWOOD V.; SYNGE, H. (Eds.). Conservation of Medicinal Plants. New York: Cambridge University Press, 1991. p. 337-358.

FELFILI, J. M.; SILVA JÚNIOR, M.C. Distribuição dos diâmetros numa faixa de cerrado na Fazenda Água Limpa (FAL) - DF. Acta Botânica Brasílica. v. 2, p. 85-166. 1988.

FELFILI, J. M. et al. Projeto biogeografia do bioma cerrado: vegetação e solos. Cadernos de Geociências, v. 12, p. 75$165,1994$.

FELFILI, J. M. et al. Estudo fenológico de Stryphnodendron adstringens (Mart.) Coville no cerrado sensu stricto da Fazenda Água Limpa no Distrito Federalo, Brasil. Revista Brasileira de Botânica. v. 22, n. 1, p. 83-90, 1999.

FELFILI, J. M. et al. Changes in the floristic composition of cerrado sensu stricto in Brazil over a nine-year period. Journal of Tropical Ecology, n. 16, p. 579-590, 2000.

FILGUEIRAS, T. S. et al. Caminhamento: um método para levantamentos florísticos qualitativos. In: IBGE. Cadernos de Geociências, n. 12, p. 39-43, 1994.

GUEDES, D. M. Resistência das Árvores do Cerrado ao Fogo: Papel da Casca como Isolante Térmico. 1993. 113 f. Dissertação (Mestrado em Ecologia) - Universidade de Brasília, Brasília, 1993.

HOMMA, A. K. O. Extrativismo vegetal na Amazônia: limites e oportunidades. Brasília: EMBRAPA - SPI, 1993. $202 \mathrm{p}$. 
INSTITUTO BRASILEIRO DE GEOGRAFIA E ESTATÍSTICA- IBGE. Economia. Agropecuária. Produção da extração vegetal e da silvicultura - PEVS. Disponível em <www.ibge.net/home/estatística/economia/ pevs/tabela1apevs.shtm>. Acesso em 2002.

MENDONÇA, R. C. et al. Flora vascular do cerrado. In: SANO, S.; ALMEIDA, S.P. (Eds.) Cerrado, ambiente e flora. Brasília: Embrapa-CPAC, 1998. p. 289-556.
MEYER, H. A. Structure, growth and drain in balance uneven-aged forests. Jornal of Forest, v. 50, p. 85-92, 1952.

MEYER, H. A. et al. Forest management. Ney York: Ronald Press, 1961. 282 p.

PELLICO NETTO, S.; BRENA, D. A. Inventário

Florestal. Curitiba: Editorado pelos Autores, 1997. 316 p.

UNESCO. Vegetação no Distrito Federal: Tempo e Espaço. Brasília: 2000. 74 p. 